\title{
Doc2 Proteins Are Not Required for the Increased Spontaneous Release Rate in Synaptotagmin-1-Deficient Neurons
}

\author{
Rocío Díez-Arazola, ${ }^{1}{ }^{\oplus}$ Marieke Meijer, ${ }^{2}$ Quentin Bourgeois-Jaarsma, ${ }^{1}{ }^{\circ}$ L. Niels Cornelisse, ${ }^{2}{ }^{\oplus}$ Matthijs Verhage, ${ }^{1,2}$ \\ and $\odot$ Alexander J. Groffen ${ }^{2}$ \\ ${ }^{1}$ Department of Functional Genomics, Center for Neurogenomics and Cognitive Research, Neuroscience Campus Amsterdam, Vrije Universiteit \\ Amsterdam, 1081 HV Amsterdam, The Netherlands, and ${ }^{2}$ Department of Clinical Genetics, Center for Neurogenomics and Cognitive Research, Amsterdam \\ UMC, Vrije Universiteit Amsterdam, 1081 HV Amsterdam, The Netherlands
}

Regulated secretion is controlled by $\mathrm{Ca}^{2+}$ sensors with different affinities and subcellular distributions. Inactivation of Syt1 (synaptotagmin-1), the main $\mathrm{Ca}^{2+}$ sensor for synchronous neurotransmission in many neurons, enhances asynchronous and spontaneous release rates, suggesting that Syt1 inhibits other sensors with higher $\mathrm{Ca}^{2+}$ affinities and/or lower cooperativities. Such sensors could include Doc2a and Doc2b, which have been implicated in spontaneous and asynchronous neurotransmitter release and compete with Syt 1 for binding SNARE complexes. Here, we tested this hypothesis using triple-knock-out mice. Inactivation of Doc2a and Doc2b in Syt1-deficient neurons did not reduce the high spontaneous release rate. Overexpression of Doc2b variants in triple-knock-out neurons reduced spontaneous release but did not rescue synchronous release. A chimeric construct in which the C2AB domain of Syt1 was substituted by that of Doc2b did not support synchronous release either. Conversely, the soluble C2AB domain of Syt1 did not affect spontaneous release. We conclude that the high spontaneous release rate in synaptotagmin-deficient neurons does not involve the binding of Doc2 proteins to Syt1 binding sites in the SNARE complex. Instead, our results suggest that the C2AB domains of Syt1 and Doc2b specifically support synchronous and spontaneous release by separate mechanisms. (Both male and female neurons were studied without sex determination.)

Significance Statement

Neurotransmission in the brain is regulated by presynaptic $\mathrm{Ca}^{2+}$ concentrations. Multiple $\mathrm{Ca}^{2+}$ sensor proteins contribute to synchronous (Syt1, Syt2), asynchronous (Syt7), and spontaneous (Doc2a/Doc2b) phases of neurotransmitter release. Genetic ablation of synchronous release was previously shown to affect other release phases, suggesting that multiple sensors may compete for similar release sites, together encoding stimulus-secretion coupling over a large range of synaptic $\mathrm{Ca}^{2+}$ concentrations. Here, we investigated the extent of functional overlap between Syt1, Doc2a, and Doc $2 \mathrm{~b}$ by reintroducing wild-type and mutant proteins in triple-knock-out neurons, and conclude that the sensors are highly specialized for different phases of release.

\section{Introduction}

Neurotransmitter secretion is induced by action potentials (APs) which activate voltage-dependent $\mathrm{Ca}^{2+}$ channels and, subsequently, $\mathrm{Ca}^{2+}$ sensor proteins in synapses (Südhof, 2013). The canonical $\mathrm{Ca}^{2+}$ sensor synaptotagmin-1 (Syt1) is anchored in the synaptic vesicle membrane. It contains two $\mathrm{C} 2$ domains which bind $\mathrm{Ca}^{2+}$ ions in a cooperative manner. Ablation of Syt1 selectively impairs synchronous neurotransmission, whereas asynchronous (slower release triggered by action potentials) and

Frank den Oudsten for excellent technical support. We thank Vincent Huson and Jurjen Broeke for their support and advice.

The authors declare no competing financial interests.

Correspondence should be addressed to Alexander J. Groffen at a.j.a.groffen@vu.nl.

https://doi.org/10.1523/JNEUROSCI.0309-19.2020

Copyright $\odot 2020$ the authors 
spontaneous release (quantal events occurring at resting membrane potential) are unaffected (Littleton et al., 1993; Broadie et al., 1994; Geppert et al., 1994). In adrenal chromaffin cells, Syt1 is important for fast-burst exocytosis but not sustained release (Voets et al., 2001). These findings prompted a "two release component" hypothesis (Broadie et al., 1994; Geppert et al., 1994; Goda and Stevens, 1994), stating that other than the canonical sensor, a second sensor can occupy release sites and codetermine the $\mathrm{Ca}^{2+}$ dependence of secretion. In Syt1-deficient neurons, a higher apparent $\mathrm{Ca}^{2+}$ sensitivity and lower cooperativity was observed (Xu et al., 2009). Similarly, Syt2 deficiency in the calyx of Held synapse strongly reduces $\mathrm{Ca}^{2+}$ cooperativity (Sun et al., 2007; Kochubey and Schneggenburger, 2011), suggesting involvement of additional release mechanisms, such as alternative sensors with relatively low cooperativities and high $\mathrm{Ca}^{2+}$ affinities.

Following Syt1, a number of additional $\mathrm{Ca}^{2+}$ sensors were identified (reviewed by Walter et al., 2011). Syt 2 and Syt 9 rescue synchronous release in Syt1-deficient neurons (Xu et al., 2007). Syt7 and Syt10 do not rescue fast release but contribute to other $\mathrm{Ca}^{2+}$-secretion coupling mechanisms in neurons and other cell types (Gustavsson et al., 2008, 2009; Cao et al., 2011). Acute Syt7 knock-down studies in Syt1-null neurons show that Syt7 contributes to asynchronous release (Bacaj et al., 2013). Syt7 enhances neurotransmission during high-frequency trains, thereby compensating for synaptic depression (Turecek et al., 2017). In chromaffin cells, Syt7 is required for sustained secretion (Schonn et al., 2008). In both neurons and chromaffin cells, the combined removal of Syt1 and Syt7 leaves a remaining release component. In particular, Syt1-deficient neurons exhibit an increased spontaneous release rate (Littleton et al., 1993; Broadie et al., 1994; Xu et al., 2009). Spontaneous release is unaffected by Syt7 knockdown and inhibited by Syt7 overexpression (Bacaj et al., 2013), again suggesting that additional release mechanisms exist.

Spontaneous neurotransmission is mediated by Doc2 proteins, which contain $\mathrm{C} 2 \mathrm{AB}$ domains similar to those of Syt 1 (Orita et al., 1995; Sakaguchi et al., 1995). The C2AB domains of Doc2b and Syt 1 share several properties: $\mathrm{Ca}^{2+}$-dependent phosphatidylserine binding, phosphatidylinositol $(4,5)$-bisphosphate and SNARE complex binding, membrane curvature induction, and fusion of SNARE-containing liposomes (Brose et al., 1992; Rickman et al., 2004; Martens et al., 2007; Groffen et al., 2010). Doc2a and Doc2b translocate from the cytosol to the plasma membrane with high $\mathrm{Ca}^{2+}$ sensitivity (Groffen et al., 2004, 2006). Doc2b may function as a high-affinity $\mathrm{Ca}^{2+}$ sensor (Groffen et al., 2006, 2010; Courtney et al., 2018) or by another mechanism (Pang et al., 2011). The N-terminal domain contains a Munc13interacting domain (MID) which mediates plasma membrane recruitment in response to diacylglycerol (Orita et al., 1997; Duncan et al., 1999). Doc2 proteins also contribute to asynchronous neurotransmission (Yao et al., 2011a). In chromaffin cells, Doc2b enhances burst exocytosis and inhibits sustained release (Friedrich et al., 2008; Pinheiro et al., 2013; Houy et al., 2017). Doc2 proteins also mediate endocrine processes in pancreatic $\beta$ cells (Miyazaki et al., 2009; Ramalingam et al., 2012), adipocytes, muscle (Fukuda et al., 2009; Ramalingam et al., 2012), and mast cells (Higashio et al., 2008). Because Syt1 and Doc2 compete for binding to SNARE complexes (Groffen et al., 2010), Doc2 proteins might be responsible for the high spontaneous release frequency observed in the absence of Syt1.
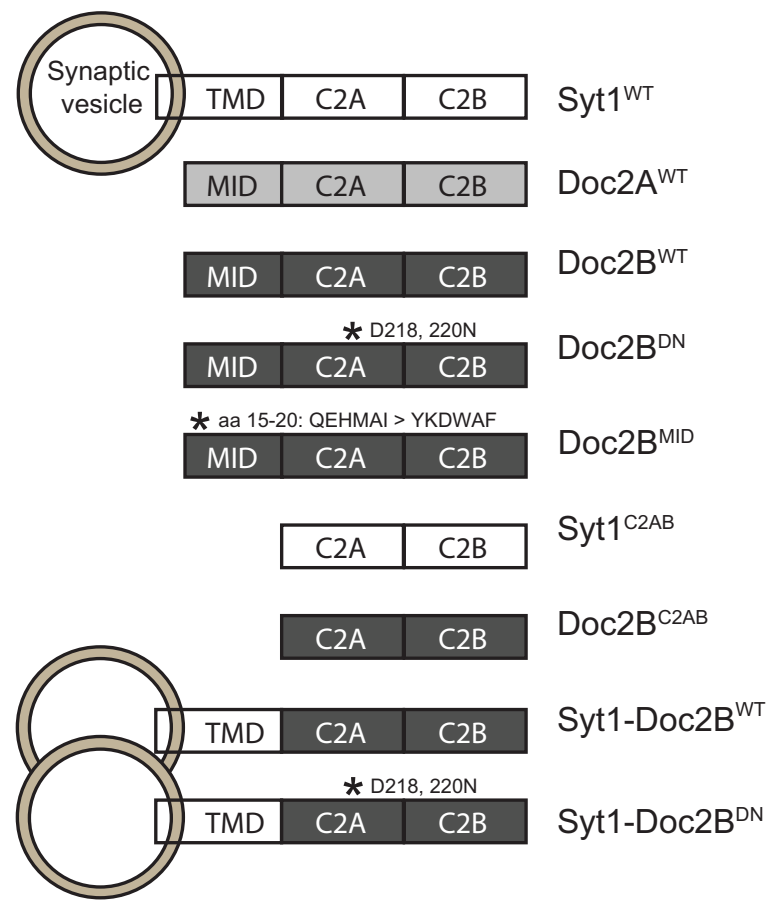

Figure 1. Schematic overview of the constructs investigated in this study, expressed from lentiviral vectors. The N-terminal domain of rat Syt1 (amino acids 1-141) is abbreviated as TMD to emphasize that it includes a transmembrane domain. The $\mathrm{N}$-terminal domains of rat Doc2a (amino acids 1-92) and Doc2b (amino acids 1-126) are designated MID to emphasize that they contain a Munc13-binding domain. C2A-C2B domains comprise residues 142- 421 (Syt1), 93-403 (Doc2a), and 127-412 (Doc2b). Asterisks indicate targeted mutations as specified.

Here, we generated mice lacking Syt1, Doc2a, and Doc2b and found that Doc2a/Doc2b do not account for the high spontaneous release rate of Syt1-deficient neurons. Our data demonstrate that the C2AB domains of Syt 1 and Doc2b are functionally distinct, suggesting separate mechanisms for evoked and spontaneous neurotransmitter release.

\section{Materials and Methods}

Generation of triple-knock-out mice. Animals were housed, bred, and handled in accordance with Dutch and European Union (EU) governmental guidelines. Protocols were approved by the Vrije Universiteit Animal Ethics and Welfare Committee (approval number FGA 11-06). Wildtype C57BL/6 mice were obtained from Charles River Laboratories. Null alleles for Syt1 (Geppert et al., 1994), Doc2a (Sakaguchi et al., 1999), and Doc2b (Groffen et al., 2010) were maintained by extensively backcrossing heterozygous mice with C57BL/6. To produce Syt1 single null mice, heterozygotes were intercrossed. To produce triple-knock-out (TKO) mice, a Doc $2 \mathrm{a}^{-1-}$ Doc $2 \mathrm{~b}^{-1-}$ Syt $1^{+/-}$mouse line was first established and then intercrossed.

Construction of lentiviral overexpression vectors. Expression vectors encoding wild-type, mutated, or hybrid variants of Syt 1 and Doc2b were constructed as illustrated in Figure 1. NCBI reference sequences are NP_001028852.2 (rat Syt1), NP_112404.1 (rat Doc2b), and NP_075226.1 (rat Doc2a).

Autapse culture electrophysiology. Autapse cultures were prepared as previously described (Groffen et al., 2010). In brief, neurons were dissociated from WT, Syt1 knock-out, and Syt1/Doc2a/Doc2b TKO mouse hippocampi at embryonic stage E18 and plated on glial microislands. Whole-cell recordings were performed at room temperature between 14 and $18 \mathrm{~d}$ in vitro. The intracellular solution was free of EGTA; it contained the following: $125 \mathrm{mM} \mathrm{K}^{+}$-gluconate, $10 \mathrm{~mm} \mathrm{NaCl}$, $4.6 \mathrm{mM} \mathrm{MgCl}_{2}$, $4 \mathrm{mM} \mathrm{K}_{2}$-ATP, $15 \mathrm{~mm}$ creatine phosphate, $10 \mathrm{U} / \mathrm{ml}$ phosphocreatine kinase, $\mathrm{pH}$ 7.30, $300 \mathrm{mOsm}$. The external medium contained the follow- 
ing (in mM): $140 \mathrm{NaCl}, 2.4 \mathrm{KCl}, 4 \mathrm{CaCl}_{2}, 4 \mathrm{MgCl}_{2}, 10$ glucose, and 10 HEPES, pH 7.30, 300 mOsm. Clampfit v10.2 (Molecular Devices) was used for offline analysis of evoked EPSCs. Data acquisition rate was 10 kHz. Miniature EPSCs were detected using Mini Analysis v6.0.3 (Synaptosoft, Inc.) using a threshold amplitude of $8 \mathrm{pA}$. Each trace was visually inspected to confirm accuracy of event detection. To calculate synchronous and asynchronous components of the EPSC charge as described, a homemade routine was written in the MATLAB environment (MathWorks; for details, see Bourgeois-Jaarsma et al., 2019). For overexpression of full-length rat Doc2a, Doc2b, and Sytl, cells were infected with lentiviral vectors encoding Doc $2 b^{\text {WT }}$, Syt $1{ }^{\text {WT }}$, Doc $2 b^{\text {DN }}$, Doc $2 b^{\text {MID }}$, Syt1 ${ }^{\mathrm{C} 2 \mathrm{AB}}$, Syt1-Doc2 $\mathrm{b}^{\text {WT }}$, or Syt1-Doc2 ${ }^{\mathrm{DN}}$ on DIV2. Throughout this paper, DN designates the D218,220N mutation in Doc2b. To control for effects caused by the lentiviral infection, we used particles encoding GFP alone. To facilitate a side-by-side comparison between all constructs, mEPSC frequencies were normalized to that of a control group included in all experiments. Recordings and analyses were performed while the identity of experimental groups was unknown to the experimenter.

Network culture and electrophysiology. Hippocampal neurons from WT, Syt1 knock-out, and Syt1/Doc2a/Doc2b TKO mice were prepared as previously described (Groffen et al., 2010). Shortly, neurons were plated at 50,000 per well on a confluent layer of glia in 12-well plates. The cells were infected with lentiviral vectors encoding GFP, Doc2b ${ }^{\text {WT }}$, Doc $2 b^{\mathrm{C} 2 \mathrm{AB}}$, Doc2 $\mathrm{a}^{\mathrm{WT}}$, Syt1 ${ }^{\mathrm{WT}}$, Syt1-Doc $2 \mathrm{~b}^{\mathrm{WT}}$, or Syt1-Doc $2 \mathrm{~b}^{\mathrm{DN}}$ on DIV2. For whole-cell recordings at DIV10-17, the neurons were analyzed with the same internal and external media as in autapses, except that the bath contained $1 \mu \mathrm{M}$ tetrodotoxin (TTX) to block $\mathrm{Na}^{+}$currents (Ascent) and $20 \mu \mathrm{M}$ gabazine (GZ) to block $\mathrm{GABA}_{\mathrm{A}}$ receptor-mediated currents (Sigma). The experimenters were blind to the expressed constructs during the recordings and analyses.

Immunocytochemistry. To verify the expression and localization of the different constructs, mouse hippocampal neurons were cultured in networks at a density of 25,000/well and transduced at DIV2 with lentiviral particles $(3 \mu \mathrm{l} /$ well). At DIV14, the cells were fixed with $4 \%$ PFA and permeabilized with $0.1 \%$ Triton X-100 in PBS for 5 min. Constructs containing the N-terminal domain of Syt1 were stained with a mouse monoclonal antibody raised against amino acids $1-12$ of rat Syt1 (1:2000 in PBS supplemented with 10\% normal goat serum; \#105221, Synaptic Systems). This antibody does not react with endogenous mouse Syt1. Synapses were stained with rabbit polyclonal E028 against Synapsin 1/2 (1:1000; Hosaka and Südhof, 1999). All constructs containing the $\mathrm{N}$-terminal domain of Doc2a/Doc2b were stained with rabbit polyclonal antibody (pAb) 13.2 (fraction 5, diluted 1:200), which was cross absorbed against Doc2a/Doc2b DKO mouse brain lysate to remove aspecific activity (Groffen et al., 2010). A mouse monoclonal against synaptobrevin-2 was used to identify synapses (1:2000, clone 69.1; Synaptic Systems). To stain the Doc $2 \mathrm{~b}^{\mathrm{C} 2 \mathrm{AB}}$ construct, which lacks the immunogen used to raise pAb 13.2, a mouse pAb anti-Doc2b (H00008447, Abnova) was used at 1:200, combined with rabbit anti-Synapsin. After labeling by secondary antibodies conjugated to Alexa 546 and Alexa 647, coverslips were mounted in Mowiol 4-88 (Aldrich) and images were acquired on an A1R confocal laser microscope (Nikon) controlled by NIS-elements AR version 4.30 (Laboratory Imaging).

Experimental design and statistical analysis. Neurons were cultured from E18-stage embryos without sex determination, thus using both male and female mice. In experiments aimed at testing the effect of overexpressed proteins, untransfected cells from the same culture batch were used as an internal control. This is important to minimize confounding effects caused by weekly experimental variations: each week uses a different culture batch from a different mouse embryo, which is reflected by weekly variations in the average mEPSC frequency of the untransfected control cells. Details of all statistical tests are listed in Table 1.

\section{Results}

To investigate whether Doc2 proteins underlie the high rate of spontaneous release in Syt1-deficient neurons, we generated TKO mice lacking Syt 1 (Geppert et al., 1994), Doc2a (Sakaguchi et al., 1999), and Doc2b (Groffen et al., 2010). TKO mice showed a similar severe phenotype as Syt1-null mice, characterized by normal embryonic development and death immediately following birth, associated with a lack of movement and respiration.

\section{Doc2a/Doc2b are not responsible for the high spontaneous release rate in Syt1-deficient neurons}

TKO hippocampal neurons were cultured either on glial microislands to induce self-innervation (autapses; Fig. 2A-E) or in network cultures (Fig. $2 F-H$ ). As expected due to the absence of Syt 1 (Geppert et al., 1994), TKO neurons showed no synchronous neurotransmission upon induction of a single action potential (Fig. $2 D, E$ ). In a direct comparison between neurons lacking Syt 1 alone (SKO; Syt1 ${ }^{-1-}$ ) or lacking all three sensors (TKO; Syt1 ${ }^{-1-}$, Doc $2 a^{-1-}$, Doc $\left.2 b^{-1-}\right)$, the peak EPSC amplitude in TKO neurons was slightly higher than that of SKO neurons ( $1.1 \pm 0.22$ and $0.47 \pm 0.06 \mathrm{nA}$, respectively; $p=0.0322$, Kruskal-Wallis and Dunn's test; Fig. 2E, left). The deletion of Doc2 proteins did not reduce the asynchronous charge (SKO, $30 \pm 4.4 \mathrm{pC}$; TKO, $63 \pm$ 13 pC; SKO + Syt1 neurons, $44 \pm 15$ pC; $p=0.0922$, KruskalWallis and Dunn's tests; Fig. 2E, right). Expression of Syt1 in SKO neurons caused much higher EPSC amplitudes (3.4 $\pm 0.9 \mathrm{nA}$; $p=0.000063$, Kruskal-Wallis and Dunn's tests). The mean spontaneous release frequency was not significantly reduced in the absence of Doc2 proteins (Fig. 2B). In previous studies, autaptic and continental Syt1-deficient neurons were shown to have different spontaneous release phenotypes (Liu et al., 2009). Therefore, we also used network cultures and recorded spontaneous mEPSC events in the presence of tetrodotoxin (TTX) and gabazine (GZ). Again, the genetic ablation of Doc2 proteins did not reduce the mini frequency (Fig. $2 F, G$ ). In both islands and networks, the expression of Syt 1 in SKO neurons reduced the mEPSC frequency to normal levels, as expected (Fig. $2 B, G ; p=0.019$ and $p=0.000035$, respectively, Dunn's tests). These results confirm earlier observations in an shRNAbased study (Pang et al., 2011), together indicating that the high mini frequency in Syt 1 knock-out neurons is not attributable to Doc2a/Doc2b. Unexpectedly, we observed a decrease in the mEPSC $10-90 \%$ rise time upon expression of Syt 1 in null neurons in networks $(p=0.01)$, but this observation was not made in autapses.

\section{Expression and subcellular distribution of recombinant proteins}

In view of the similar SNARE-binding and phospholipid-binding activities of Syt 1 and Doc2, we also investigated the effect of Doc2 overexpression on spontaneous release. In addition to wild-type Syt1, Doc2a, and Doc2b, we designed mutated and hybrid variants of these proteins (see Fig. 1 for an overview). To test the expression and localization of these constructs, neurons expressing them were stained with antibodies against Doc2 and synaptic markers (Fig. 3). Most Doc2 constructs were homogeneously distributed throughout the soma and neurite extensions. In addition, Doc $2 b^{D N}$ was found at the plasma membrane. Despite the lack of a synaptic targeting signal, immunoreactivity was also detectable in synapses (Fig. 3, arrowheads). Likewise, all constructs containing the $\mathrm{N}$-terminal domain of Syt 1 were readily detectable by immunocytochemistry. As predicted by the trafficking signals in the N-terminal domain (Kang et al., 2004), and consistent with previous experiments (Xue et al., 2015), these constructs were effectively targeted to synapses (Fig. 4). 


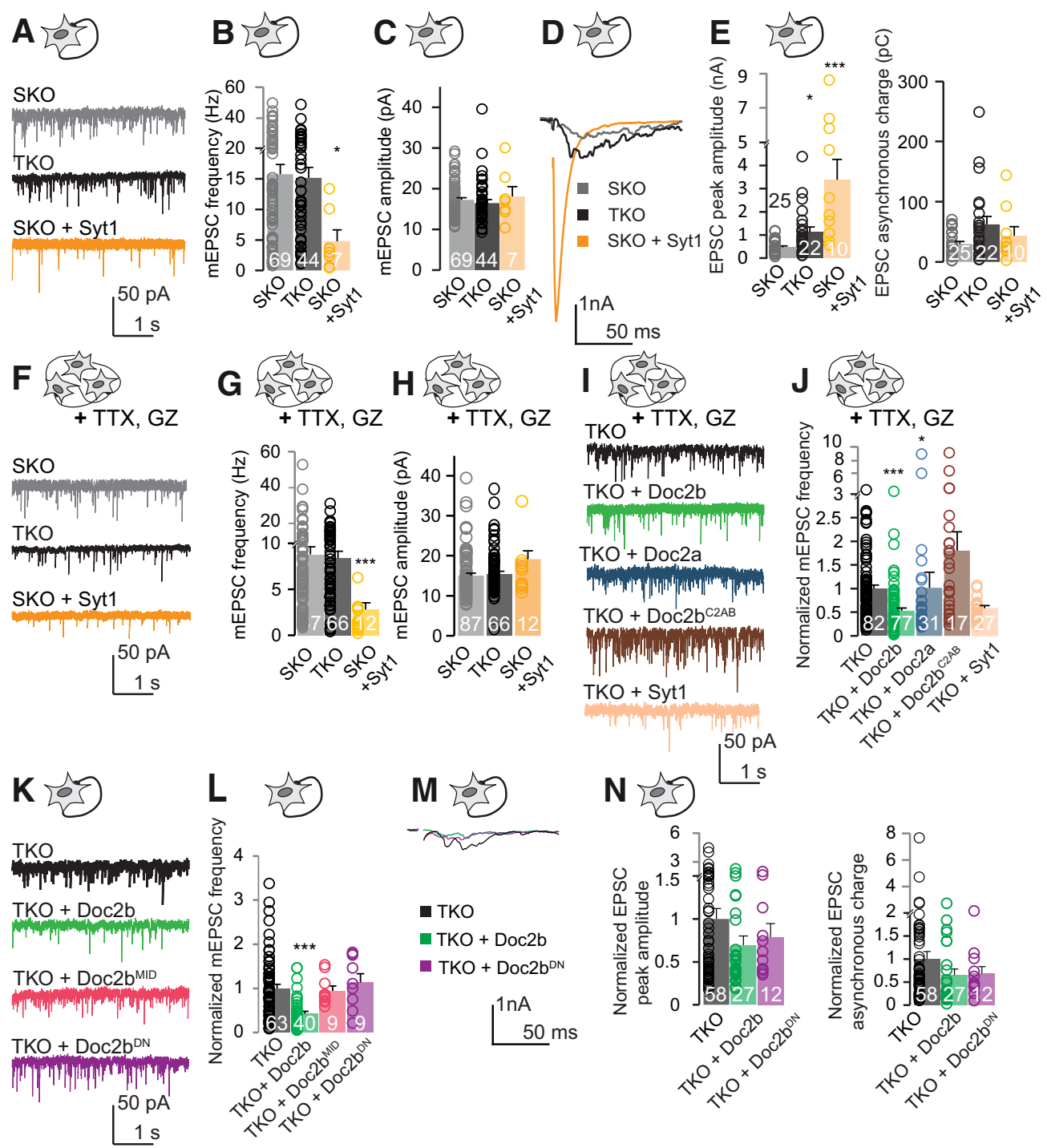

Figure 2. Doc2 proteins are not responsible for the high frequency of spontaneous release in SKO neurons, and the MID is necessary for an inhibitory role of Doc $2 \mathrm{~b}$ overexpressed in TKO neurons. $\boldsymbol{A}-\boldsymbol{C}$, Representative traces $(\boldsymbol{A})$, average frequency $(\boldsymbol{B})$, and amplitude $(\boldsymbol{C})$ of spontaneous mEPSC recorded from autaptic cultures of SKO, TKO, or SKO neurons overexpressing Syt1. $\boldsymbol{D}, \boldsymbol{E}$, Representative traces $(\boldsymbol{D})$ and average peak amplitude ( $\boldsymbol{E}$, left) and asynchronous charge ( $\boldsymbol{E}$, right) of evoked EPSCs recorded from autaptic neurons with the same genotypes. $\boldsymbol{F}-\boldsymbol{H}$, Representative traces $(\boldsymbol{F})$, average frequency $(\boldsymbol{G})$, and amplitude $(\boldsymbol{H})$ of spontaneous mEPSCs recorded from network cultures of SK0, TK0, or SKO neurons overexpressing Syt1. TTX $(1 \mu \mathrm{M})$ and GZ $(20 \mu \mathrm{M})$ were added to the extracellular solution to prevent network activity and isolate excitatory events. $\boldsymbol{I}, \boldsymbol{J}$, Representative traces $(\boldsymbol{I})$ and average frequency $(\boldsymbol{J})$ of spontaneous mEPSCs recorded from network cultures of TKO neurons overexpressing Doc2b, Doc2a, Doc2b ${ }^{\mathrm{C} 2 \mathrm{AB}}$, or Syt1 in the presence of $1 \mu \mathrm{M}$ TTX and $20 \mu \mathrm{M}$ GZ. $K, L$, Representative traces $(\boldsymbol{K})$ and average frequency $(\boldsymbol{L})$ of spontaneous mEPSCs recorded from autaptic cultures of TKO neurons overexpressing Doc $2 \mathrm{~b}$, Doc $2 b^{\mathrm{MID}}$, Doc $2 \mathrm{~b}^{\mathrm{DN}}$, or Syt1. $\boldsymbol{M}, \boldsymbol{N}$, Representative traces recorded from TKO neurons overexpressing Doc2b or Doc $2 b^{D N}(\boldsymbol{M})$ and average peak amplitude ( $\boldsymbol{N}$, left) and asynchronous charge $(\boldsymbol{N}$, right) of evoked EPSCs. J, $\boldsymbol{L}, \boldsymbol{N}$, Values of cells expressing various constructs were normalized to the mean value of untransfected cells. Error bars indicate SEs. Cell numbers are indicated within bars. ${ }^{*} p<0.05,{ }^{* * *} p<$ 0.001 .

\section{Doc2b overexpression inhibits spontaneous release in TKO neurons}

Interestingly, Doc2b overexpression caused a twofold reduction of the mEPSC frequency in TKO islands (from 100\% in untransfected cells to $46 \pm 5 \%$ in Doc $2 \mathrm{~b}^{\mathrm{WT}}$-expressing cells; $p=$ 0.000006, Kruskal-Wallis and Dunn's tests; Fig. 2 K, L, compare green and black). The data are also provided in Table 1. A similar reduction was observed in Doc2b-overexpressing networks (to $50 \pm 5 \%$ of controls; $p=0.000001$, Kruskal-Wallis and Dunn's tests; Fig. 2I, J, green versus black). This inhibitory effect was specific for Doc2b (Fig. $2 J$ ), even though Doc2a was present in synapses (Fig. 3). Although Dunn's test reported a different data distribution for Doc2a $(p=0.015)$, the mean
mEPSC frequency was identical to that of untransfected neurons, so we conclude that Doc2a did not inhibit spontaneous release. The inhibitory effect of Doc $2 b$ was accompanied by a slightly reduced asynchronous release component, but this effect was not significant (Fig. $2 M, N$, right, green versus black). Synchronous release remained absent (Fig. $2 \mathrm{M}, \mathrm{N}$, green versus black). Thus, in TKO neurons, overexpression of Doc2b inhibits spontaneous release.

\section{Spontaneous release inhibition by Doc2b depends on its Munc13-interacting domain}

In wild-type neurons, Doc2b overexpression did not inhibit spontaneous release, as reported previously (Groffen et al., 2010). 
We hypothesized that Doc2, which is soluble in the cytoplasm, cannot compete efficiently with Syt1, which is anchored to the vesicle membrane of wild-type cells. In addition to $\mathrm{Ca}^{2+}$, Munc13 can also target Doc2b to the plasma membrane by its N-terminal MID (Orita et al., 1997; Duncan et al., 1999; Friedrich et al., 2013; Houy et al., 2017). To test whether Doc2b-mediated inhibition of spontaneous release requires Munc13 binding, the N-terminal domain was either deleted or mutated. Upon deletion of the $\mathrm{N}$-terminal domain, the $\mathrm{C} 2 \mathrm{AB}$ fragment of Doc $2 b$ (Doc $2 b^{\mathrm{C} 2 \mathrm{AB}}$ ) lost its inhibitory effect on spontaneous release (Fig. 2J). Likewise, when the Munc13 interaction was blocked by a previously characterized mutation at amino acids 15-20 (Orita et al., 1997; Mochida et al., 1998; Groffen et al., 2004), full-length Doc2b lost its ability to inhibit spontaneous release (Fig. $2 L$, Doc $\left.2 b^{\mathrm{MID}}\right)$. The subcellular distribution of the Doc $2 b^{\text {MID }}$ mutant was not discernible from Doc $2 b^{\text {WT }}$, including immunoreactivity in synapses (Fig. 3). Thus, Munc13 interaction is not required for synaptic delivery of Doc2b. Instead, the mutation may affect the distribution of Doc2 or Munc13 within synaptic microdomains, or alter the functional activity of either protein. Finally, a mutation that mimics the effect of $\mathrm{Ca}^{2+}$ binding to the C2A domain (Groffen et al., 2004; Friedrich et al., 2008) did not inhibit spontaneous release (Fig. $2 L$, Doc $2 \mathrm{~b}^{\mathrm{DN}}$ ). The asynchronous release component was not reduced by overexpression of this mutant either (Fig. 2N, right). Consistent with other studies, Doc $2 b^{\text {DN }}$ was enriched at the plasma membrane of transfected neurons (Groffen et al., 2006; Xue et al., 2015; Houy et al., 2017; BourgeoisJaarsma et al., 2019). Together, we conclude that the inhibitory activity of Doc $2 \mathrm{~b}$ in TKO cells requires its Munc13 binding activity and is lost after neutralization of the $\mathrm{Ca}^{2+}$-binding aspartates D218 and D220 in the C2A domain.

\section{Doc2b overexpression in SKO neurons}

Similar to the aforementioned experiments in TKO cells, fulllength Doc2a and Doc2b were also expressed in SKO neurons lacking only Syt1. As previously reported (Geppert et al., 1994), SKO autapses showed extremely small EPSC amplitudes (Fig. $5 D, E)$, which were effectively rescued upon reintroduction of Syt1 (the amplitude increased 10-fold after Syt1 expression in SKO neurons, gray versus orange; $p=0.0008$, Kruskal-Wallis and Dunn's tests). Overexpression of Doc $2 \mathrm{~b}$ failed to rescue the EPSC amplitude, which was almost identical to that of SKO neurons (gray versus yellow). Overexpression of Doc2b reduced the mini frequency in SKO networks to $65 \pm 10 \%$ (Fig. $5 F, G ; p=0.0387$, Kruskal-Wallis and Dunn's tests), but this effect was not observed in autapses, where Doc2boverexpressing cells had a mini frequency of $90 \pm 20 \%$ relative to untransfected controls (Fig. $5 A, B$, gray versus yellow; $p=$ 0.7289 , Kruskal-Wallis and Dunn's tests). Doc2a overexpression did not affect the spontaneous release frequency (Fig. $5 F)$, although an increase in mEPSC amplitude was observed (Fig. 5H; $p=0.0475$, Kruskal-Wallis and Dunn's tests). Finally, as expected, overexpression of wild-type Syt1 readily decreased the mini frequency in both networks (to $30 \pm 8 \%$ of controls; Fig. 5F; $p=0.0016$, Kruskal-Wallis and Dunn's tests) and autaptic neurons (to $22 \pm 7 \%$ of controls; Fig. $5 B$; $p=0.0027$, Kruskal-Wallis and Dunn's tests). Together, the results suggest that Doc2b does not support secretion at Syt1dependent release sites: neither during the synchronous phase (measured as EPSCs) nor during rest (mEPSCs).

\section{The Syt1 N-terminal domain is essential for spontaneous release inhibition}

Previous studies suggested that the transmembrane domain (TMD) is not essential for the fusogenic activity of Syt 1 (Mar- 


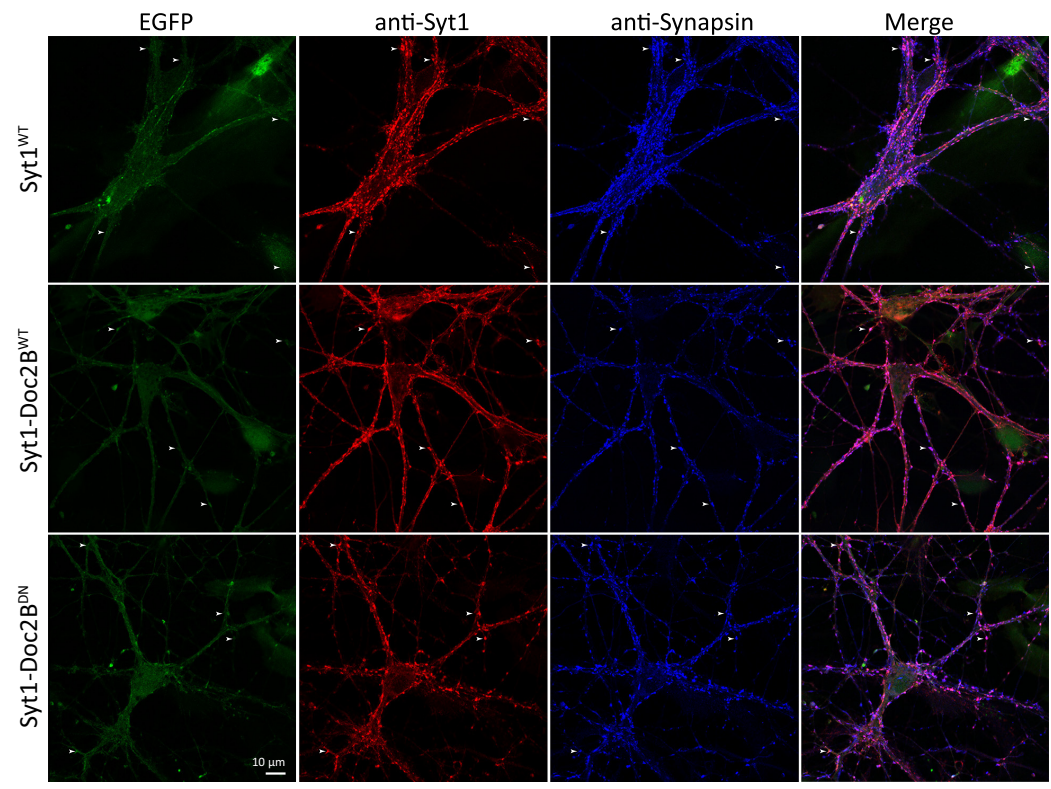

Figure 4. Overexpressed Syt1 and Syt1-Doc2b are targeted to synapses. Rat Syt1 ${ }^{\text {WT }}$, Syt1-Doc2b ${ }^{\text {WT }}$, or Syt1-Doc2b ${ }^{\text {DN }}$ was expressed in wild-type mouse hippocampal neurons. EGFP was expressed as a separate protein from an internal ribosomal entry site. After fixing at DIV14, the cells were stained with a monoclonal antibody specific for amino acids 1-12 of rat Syt1. This antibody does not react with mouse Syt1. Synapsin-1/2 was stained to mark synapses. Many synapses express recombinant Syt1; a few examples are highlighted by arrowheads.

tens et al., 2007; Hui et al., 2009; Wang et al., 2011), although it may contribute to vesicle docking (de Wit et al., 2009) and recycling (Yao et al., 2011b). Interestingly, overexpression of the $\mathrm{C} 2 \mathrm{AB}$ fragment of Syt 1 (Syt $1^{\mathrm{C} 2 \mathrm{AB}}$ ) in autaptic neurons had no significant effect on the spontaneous release rate $(80 \pm$ $10 \%$ of control; Fig. $5 B ; p>0.9999$, Kruskal-Wallis and Dunn's tests). Thus, the TMD is essential for spontaneous release inhibition by Syt 1 .

\section{The C2AB fragment of Syt1 synchronizes fusion during sustained activity}

Overexpression of Syt $1^{\mathrm{C} 2 \mathrm{AB}}$ in Syt1-null neurons had a minor effect on the EPSC amplitude (1.7-fold increase in SKO + Syt $1{ }^{\mathrm{C} 2 \mathrm{AB}}$; Fig. $5 E ; p=0.1640$, Kruskal-Wallis and Dunn's test). During trains of 100 action potentials at $5 \mathrm{~Hz}, 50 \%$ of the neurons overexpressing Syt $1{ }^{\mathrm{C} 2 \mathrm{AB}}$ showed a remarkable facilitation of the EPSC amplitude, increasing from $0.8 \pm 0.2 \mathrm{nA}$ (first AP) to $2.5 \pm$ 0.4 nA (10th AP; Fig. 5I-K; $p=0.000244$, Wilcoxon matchedpairs signed rank test), thereby reaching similar amplitudes as SKO neurons overexpressing full-length Syt1 (increasing from $2.7 \pm 0.6 \mathrm{nA}$ after the first AP to $3.1 \pm 0.4 \mathrm{nA}$ after the 10 th AP; $p=0.9860$, Kruskal-Wallis and Dunn's test). A small increase was observed in Syt1-null neurons (first pulse, $0.66 \pm 0.18 \mathrm{nA}$; 10th pulse, $0.9 \pm 0.18 \mathrm{nA}$; Fig. $5 \mathrm{~J}$, left; $p=0.021545$, Wilcoxon matched-pairs signed rank test); however, the amplitude of Syt1null neurons did not reach similar levels as Syt1-null neurons overexpressing full-length Syt 1 ( $p=0.0006$, Kruskal-Wallis and Dunn's test). The effect of Syt $1{ }^{\mathrm{C} 2 \mathrm{AB}}$ was accompanied by a reduction of the $10-90 \%$ rise time of the EPSCs that matched the $10-90 \%$ rise time of the 10th pulse of Syt1-null neurons overexpressing full-length Syt1 (SKO + Syt $1^{\mathrm{C} 2 \mathrm{AB}}$, first pulse: $9.12 \pm$ $3.12 \mathrm{~ms}$, 10th pulse: $2.43 \pm 0.16 \mathrm{~ms}$; SKO + Syt $^{\mathrm{WT}}$, first pulse: $2.14 \pm 0.21 \mathrm{~ms}$, 10th pulse: $2.62 \pm 0.3 \mathrm{~ms}$; Fig. 5J, right; $p=$ 0.390805 , Kruskal-Wallis and Dunn's test). In contrast, SKO neurons did not show a reduction of the $10-90 \%$ EPSC rise time upon synaptic activity (first pulse, $20.9 \pm$ $2.6 \mathrm{~ms} ; 10$ th pulse, $21.2 \pm 3.54 \mathrm{~ms} ; p>$ 0.9999, Wilcoxon matched-pairs signed rank test), indicating that the release remained asynchronous. We conclude that overexpression of the $\mathrm{C} 2 \mathrm{AB}$ fragment of Syt1 is sufficient for driving synchronous release in a subset of neurons, and that this effect depends on synaptic activity.

\section{Intrinsic differences in fusion enhancement by Doc $2 b^{\mathrm{C} 2 \mathrm{AB}}$ and Syt ${ }^{\mathrm{C} 2 \mathrm{AB}}$}

Given the high degree of biochemical similarity between the Syt ${ }^{\mathrm{C} 2 \mathrm{AB}}$ and Doc $2 b^{\mathrm{C} 2 \mathrm{AB}}$ fragment, we next investigated whether a hybrid construct, composed of the N-terminal domain of Syt 1 and the $\mathrm{C} 2 \mathrm{AB}$ domain of Doc $2 \mathrm{~b}$, substitutes for wild-type Syt1 in synchronous neurotransmitter release. In hippocampal autapses, the high spontaneous release rates of Syt1-null neurons remained high after expression of the hybrid construct, and the mEPSC rise time was reduced compared with that of Syt1-null neurons (Fig. 6A, $B ; p=0.01$, Kruskal-Wallis and Dunn's test). A 1.7-fold increase in mEPSC frequency was observed in cells expressing the Syt1-Doc2B ${ }^{\text {DN }}$ hybrid $(p=0.01054$, KruskalWallis and Dunn's test). Moreover, an increase in the mEPSC amplitude was observed in this group ( $p=0.0035$, KruskalWallis and Dunn's test). Synchronous neurotransmission was not rescued by the Syt1-Doc2b hybrid, nor by the mutant variant Syt1-Doc2 $\mathrm{B}^{\mathrm{DN}}$ (Fig. 6D,E), even though the hybrid constructs were targeted to synapses (Fig. 4). In network cultures, Syt1Doc $2 b^{D N}$ expression did not significantly change the mEPSC frequency and amplitude (Fig. $6 G ; p=0.2614$ and 0.7487 , respectively, Kruskal-Wallis and Dunn's test). Together, we conclude that the $\mathrm{C} 2 \mathrm{AB}$ domains of Syt 1 and Doc $2 \mathrm{~b}$ are not functionally interchangeable.

\section{Discussion}

Previous studies reported a strong increase in the frequency of spontaneous neurotransmitter release events in neurons lacking Syt1 (Littleton et al., 1993; Broadie et al., 1994; Xu et al., 2009). To explain this phenomenon, it has been hypothesized that Doc2 proteins occupy vacant Syt1-dependent release sites, increasing their apparent $\mathrm{Ca}^{2+}$ sensitivity and thereby causing a higher release probability at low resting $\mathrm{Ca}^{2+}$ concentrations (Walter et al., 2011). Here, we tested this hypothesis by triple homologous gene targeting of Syt1, Doc2a, and Doc2b in mouse neurons. We conclude that the high spontaneous release rate in Syt 1 cells does not require Doc2a/Doc2b activity. This finding is consistent with earlier knock-down experiments (Pang et al., 2011). Our data show that the functional differences between Doc2b and Syt 1 are not limited to their different $\mathrm{N}$-terminal domains but are also encoded in the $\mathrm{C} 2 \mathrm{AB}$ domain. In particular, the $\mathrm{C} 2 \mathrm{AB}$ domain of Doc2b cannot functionally replace that of Syt 1 , as demonstrated by the inability of hybrid Syt1-Doc2b to support synchronous fusion. In a previous study where presynaptic neurons were locally stimulated in a network configuration, similar Syt1-Doc2b chimers also did not support synchronous fusion (Xue et al., 2015). Interestingly, this study 


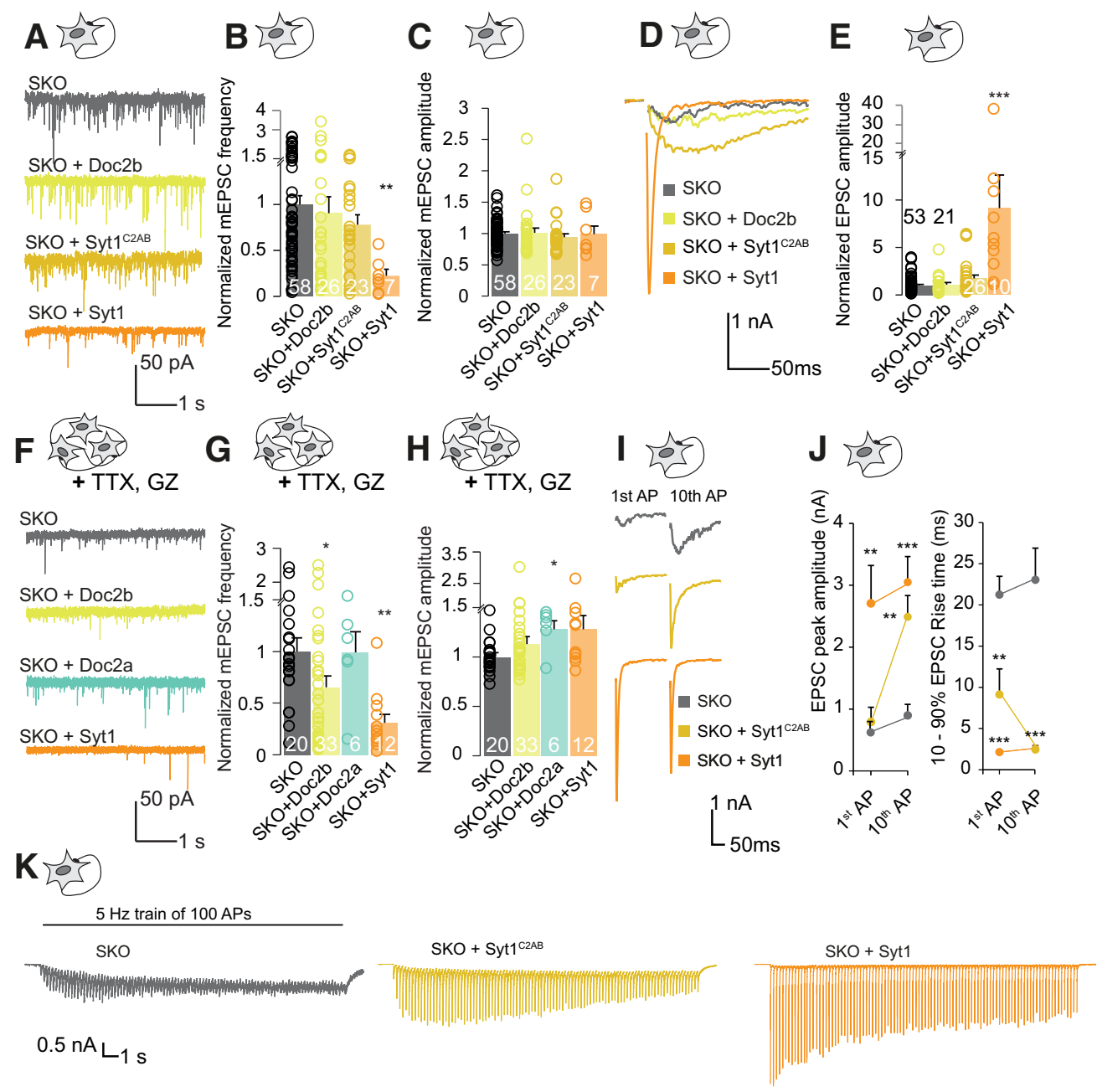

Figure 5. The transmembrane domain of Syt1 is necessary for its inhibitory role on mEPSCs in hippocampal neurons. To control for variation between independent experiments, $\mathrm{mEPSC}$ frequencies and amplitudes were normalized to the mean value of untransfected neurons measured in the same experiment. $\boldsymbol{A}-\boldsymbol{C}$, Representative traces $(\boldsymbol{A})$, average frequency $(\boldsymbol{B})$, and amplitude (C) of spontaneous mEPSCS recorded from Syt1 SKO neurons in autaptic culture, untransfected or overexpressing Doc2b, Syt1 ${ }^{\text {C2AB }}$, or Syt1. D, E, Representative traces (D) and average peak amplitude $(\boldsymbol{E})$ of evoked EPSCS recorded from autaptic SKO neurons, untransfected or overexpressing Doc2b, Syt1 ${ }^{\text {C2AB }}$, or Syt1. $\boldsymbol{F}-\boldsymbol{H}$, Representative traces $(\boldsymbol{F})$, average frequency $(\boldsymbol{G})$, and amplitude $(\boldsymbol{H})$ of spontaneous mEPSCs recorded from network cultures of SKO neurons, untransfected or overexpressing Doc2b, Doc2a, or Syt1. To prevent network activity and isolate excitatory events, TTX (1 $\mu \mathrm{M}$ ) and GZ $(20 \mu \mathrm{M})$ were added to the extracellular solution. I, Representative traces of the first and the 10th evoked EPSCs from a train of $100 \mathrm{APs}$ elicited at $5 \mathrm{~Hz}$, recorded from autaptic SKO neurons, untransfected or overexpressing Syt1 ${ }^{\mathrm{C} 2 \mathrm{AB}}$ or Syt1. J, Average peak amplitude (left) and $10-90 \%$ rise time (right) of the first and 10th evoked EPSC from the train ( $n=15$ untransfected, 13 Syt ${ }^{\text {C2AB }}$-expressing and 7 Syt1-expressing cells). $\boldsymbol{K}$, Representative traces showing the full EPSC recording throughout the $5 \mathrm{~Hz}$ train. Error bars indicate SEs. Cell numbers are indicated within bars. ${ }^{*} p<0.05,{ }^{* *} p<0.01,{ }^{* * *} p<0.001$.

also demonstrated that the $\mathrm{C} 2 \mathrm{~B}$ domain of Doc2b exhibits slower kinetics than Syt1. Thus, differences in both the kinetics and affinity of $\mathrm{Ca}^{2+}$ and phospholipid binding likely contribute to the divergent $\mathrm{C} 2 \mathrm{AB}$ domain activity.

It is conceivable that different sensors have evolved to mediate specialized $\mathrm{Ca}^{2+}$-secretion coupling processes in different subcellular compartments. Moreover, different types of neurons may bear different sets of presynaptic proteins to regulate vesicle release. In line with this, a recent study has shown that Doc2a and Doc $2 \mathrm{~b}$ are differentially expressed in the brain, facilitating glutamatergic and GABAergic spontaneous release, respectively (Courtney et al., 2018). Upon overexpression, however, Doc2b restored the spontaneous release frequency in Doc2a-deficient glutamatergic cells and vice versa, suggesting functional redundancy (Courtney et al., 2018). Interestingly, our data now indicate a functional difference between Doc2a and Doc2b: Doc2b inhibited the spontaneous release rate, whereas Doc2a did not. This observation was made in both TKO and SKO networks (Figs. 2I,J, 5F, G).
The inhibitory effect of Doc2b was evident in SKO network cultures, but not autapses. As a key difference, networks are mixed cultures that contain GABAergic cells. The long-term spontaneous release of GABA can regulate mEPSC frequencies of glutamatergic cells in a mixed culture (Wierda and Sørensen, 2014). In several studies, this effect has presumably masked the high mEPSC frequency of Syt1-deficient neurons (Liu et al., 2009; Wierda and Sørensen, 2014). In a similar manner, it is possible that the inhibitory effect of Doc $2 \mathrm{~b}$ is an indirect consequence of increased spontaneous GABA release. Because we included gabazine to block $\mathrm{GABA}_{\mathrm{A}}$ receptors, this effect would have to be mediated by metabotropic $\mathrm{GABA}_{\mathrm{B}}$ receptors. Interestingly, mixed culture effects may also help explain why experiments in locally stimulated networks suggest a role for Doc2b in asynchronous release (Yao et al., 2011a), whereas autapse experiments do not (Groffen et al., 2010).

At physiological extracellular $\mathrm{Ca}^{2+}$ concentrations $\left(\left[\mathrm{Ca}^{2+}\right]_{0}\right)$, both Syt 1 and Doc $2 \mathrm{~b}$ are required for driving spontaneous release in inhibitory neurons, whereas Syt 1 is dispensable for facilitating 


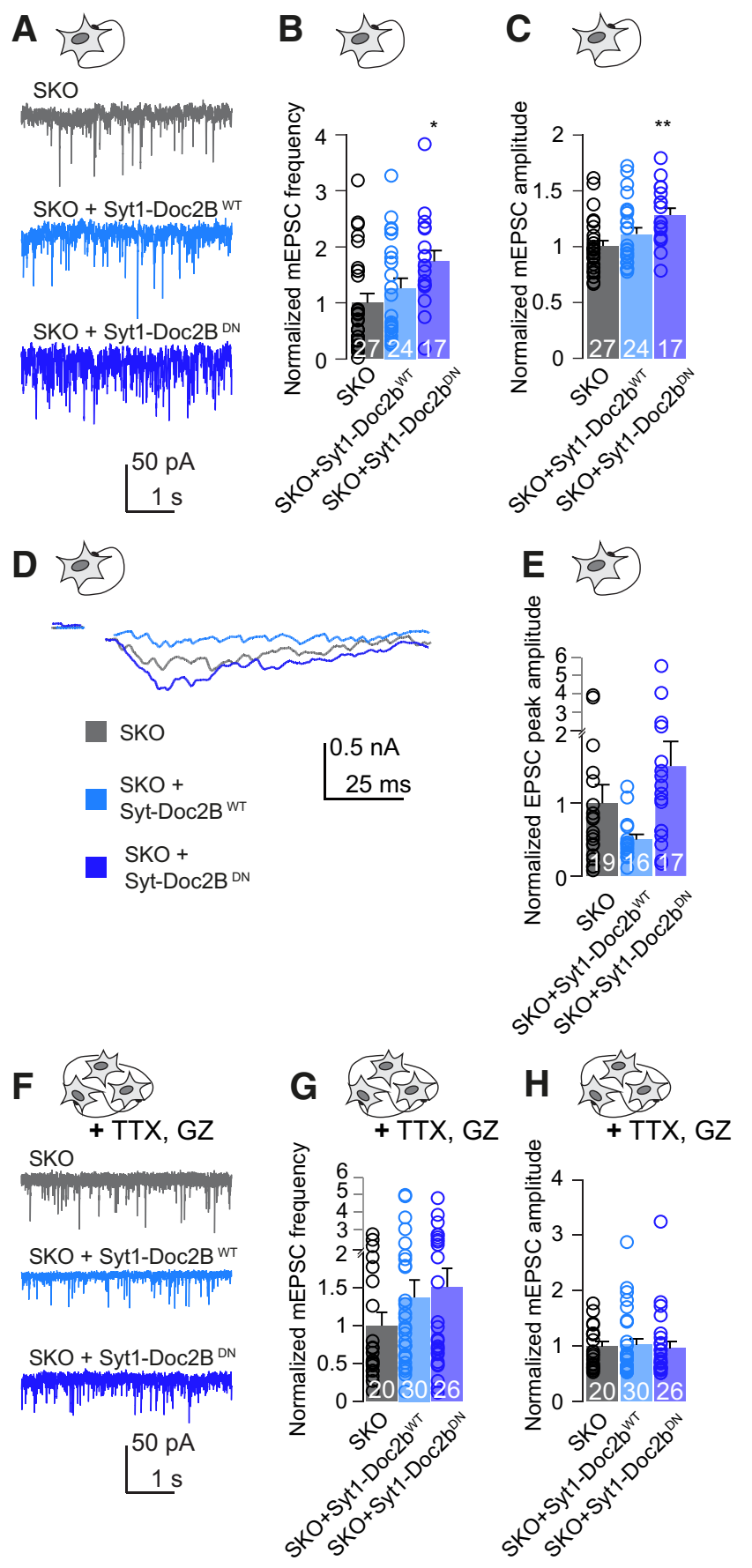

Figure 6. The $22 A B$ domain of Doc $2 b$ is not capable of replacing that of Syt 1 in synchronous neurotransmitter secretion. To control for variation between independent experiments, $\mathrm{mEPSC}$ frequencies and amplitudes were normalized to the mean value of untransfected neurons measured in the same experiment. $\boldsymbol{A}-\boldsymbol{C}$, Representative traces $(\boldsymbol{A})$, average frequency $(\boldsymbol{B})$, and amplitude $(\boldsymbol{C})$ of spontaneous $\mathrm{mEPS}$ (s recorded from autaptic cultures of $S K O$ neurons overexpressing Syt1-Doc2b ${ }^{\mathrm{WT}}$ or Syt1-Doc2b ${ }^{\mathrm{DN}}$. D, E, Representative traces $(\boldsymbol{D})$ and average peak amplitude $(\boldsymbol{E})$ of evoked EPSCs recorded from autaptic SKO neurons overexpressing Syt1Doc $2 b^{\text {WT }}$ or Syt1-Doc $2 b^{\text {DN }}$. $\boldsymbol{F}-\boldsymbol{H}$, Representative traces $(\boldsymbol{F})$, average frequency $(\boldsymbol{G})$, and amplitude $(\boldsymbol{H})$ of spontaneous mEPSCS recorded from network hippocampal cultures of SKO overexpressing Syt1-Doc $2 b^{\text {WT }}$ or Syt1-Doc $2 b^{\text {DN }}$. TTX $(1 \mu \mathrm{M})$ and GZ $(20 \mu \mathrm{M})$ were added to the extracellular solution to prevent network activity and isolate excitatory events. Error bars indicate SE. Cell numbers are indicated in bar graphs. ${ }^{*} p<0.05,{ }^{* *} p<0.01$.

minis in glutamatergic neurons, an action that depended on Doc2a alone (Courtney et al., 2018). Thus, it is possible that the promoting role of Syt 1 on spontaneous release described by Xu et al. (2009) is restricted to higher $\left[\mathrm{Ca}^{2+}\right]_{0}$. Our results support a multisensor model where specialized $\mathrm{Ca}^{2+}$ sensors act together to determine the $\mathrm{Ca}^{2+}$-dependent synaptic release rate, each contributing to a distinct kinetic component of the overall release in hippocampal synapses. This model is compatible with the previously described two-sensor model (Goda and Stevens, 1994), which already noted that the "second sensor" could represent a collection of molecules. We suggest that at least three classes of sensors underlie synaptic secretion. The first class of sensors (Syt1, Syt2, or Syt9) promotes fast membrane fusion during action potential-evoked $\mathrm{Ca}^{2+}$ transients but does not support secretory events at resting $\mathrm{Ca}^{2+}$, at least not in excitatory neurons (Courtney et al., 2018). A second class of sensors is responsible for the "asynchronous" release of neurotransmitters evoked by action potentials. Syt7 was shown to belong to this class (Bacaj et al., 2013; Luo and Südhof, 2017); however, it is not responsible for increased spontaneous release in Syt1-deficient neurons. A third class, including Doc $2 \mathrm{~b}$, does not support synchronous fusion but promotes secretory events in the absence of action potentials. Doc2 proteins have also been proposed to play a role in asynchronous release (Yao et al., 2011a), although this finding was not reproducible in our hands, possibly due to different experimental conditions. A recent study also showed a novel role for Doc2 proteins as part of the $\mathrm{Ca}^{2+}$ sensor machinery that drives augmentation (Xue et al., 2018). Finally, the mechanism of spontaneous release in TKO neurons remains to be identified. It is possible that this class comprises a fourth class of $\mathrm{Ca}^{2+}$-sensing molecules, but alternatively, sensorless fusion may occur. The likelihood of spontaneous release events is regulated by extracellular $\mathrm{Ca}^{2+}$ concentrations (Xu et al., 2009; Smith et al., 2012), the stochastic opening of voltage-dependent channels (Ermolyuk et al., 2013), or intracellular $\mathrm{Ca}^{2+}$ channels (Llano et al., 2000; Emptage et al., 2001).

In wild-type neurons, Doc2b positively contributes to spontaneous release (Groffen et al., 2010), and its overexpression does not inhibit the mini frequency, suggesting that endogenous Doc $2 b$ is not rate limiting. Overexpression of Doc2b in the $a b-$ sence of Syt1, however, revealed a negative contribution to spontaneous release. The inhibitory activity of Doc $2 \mathrm{~b}$ required an intact $\mathrm{N}$-terminal domain and was blocked by mutations in the Munc13-interacting domain. In chromaffin cells, Doc2b also has mixed positive and inhibitory effects on regulated secretion, both of which are dependent on the MID domain (Houy et al., 2017). The domain likely contributes to local enrichment of Doc2b at release sites, even though the Doc $2 b^{\text {MID }}$ mutant is expressed in synaptic structures. The MID domains of Doc2a and Doc2b are highly conserved, and both isoforms bind to Munc13 (Orita et al., 1997; Duncan et al., 1999). Local accumulation also appears to be relevant for Syt1-dependent inhibition of spontaneous release, because this activity is abolished by deletion of the transmembrane domain. Thus, in general, $\mathrm{Ca}^{2+}$ sensors may inhibit spontaneous release by binding to release sites under conditions in which the $\mathrm{C} 2 \mathrm{AB}$ domain is not activated. These conditions may include low intracellular $\mathrm{Ca}^{2+}$ concentrations, sensor protein mistargeting, or mutations that block fusogenic activity. In line with this model, minimal fragments comprising the $\mathrm{C} 2 \mathrm{AB}$ domain of Syt 1 and Doc $2 \mathrm{~b}$ are sufficient to drive membrane fusion in reconstituted SNARE liposomes (Martens et al., 2007; Hui et al., 2009; Groffen et al., 2010; Wang et al., 2011). The C2AB fragment of Doc $2 \mathrm{~b}$ has also been shown to interact with opposing membranes, directly participating in $\mathrm{Ca}^{2+}$-dependent and phosphatidylserinedependent stalk formation and hemifusion in a SNARE-free assay (Brouwer et al., 2015). 
Table 1. Summary of data and statistical analyses

\begin{tabular}{|c|c|c|c|c|c|c|c|c|c|c|c|c|}
\hline & Parameter & df & Test $/ H$ & & df & Test $/ H$ & & df & Test $/ H$ & & df & Test $/ H$ \\
\hline \multicolumn{13}{|l|}{ Figure 2} \\
\hline Genotype autaptic cells $(n)$ & $\mathrm{mEPSC}$ frequency $(\mathrm{Hz})$ & & Kruskal-Wallis & mEPSC amplitude (pA) & & Kruskal-Wallis & mEPSC rise time (ms) & & Kruskal-Wallis & mEPSC decay time (ms) & & Kruskal-Wallis \\
\hline SKO (control; 69) & $15.7 \pm 1.6$ & & & $17.3 \pm 0.5$ & & & $1.8 \pm 0.05$ & & & $2.8 \pm 0.1$ & & \\
\hline ТКО (44) & $\begin{array}{l}15.2 \pm 1.7 \\
\quad(p>0.9999)\end{array}$ & 2 & 7.032 & $\begin{array}{l}16.5 \pm 0.8 \\
\quad(p=0.3836)\end{array}$ & 2 & 1.920 & $1.9 \pm 0.1(p>0.9999)$ & 2 & 7.750 & $3 \pm 0.1(p=0.3654)$ & 2 & 3.017 \\
\hline SKO + Syt1 (7) & $\begin{array}{l}4.8 \pm 1.9^{*} \\
\quad(p=0.0190)\end{array}$ & 2 & 7.032 & $\begin{array}{l}18.1 \pm 2.4 \\
\quad(p>0.9999)\end{array}$ & 2 & 1.920 & $1.4 \pm 0.2(p=0.0232)$ & 2 & 7.750 & $2.6 \pm 0.4(p=0.8000)$ & 2 & 3.017 \\
\hline Genotype continental cells $(n)$ & $\mathrm{mEPSC}$ frequency $(\mathrm{Hz})$ & & Kruskal-Wallis & mEPSC amplitude (pA) & & Kruskal-Wallis & mEPSC rise time (ms) & & Kruskal-Wallis & mEPSC decay time (ms) & & Kruskal-Wallis \\
\hline SKO (control; 87) & $8.8 \pm 0.8$ & & & $15 \pm 0.6$ & & & $1.9 \pm 0.1$ & & & $2.8 \pm 0.1$ & & \\
\hline TKO (66) & $\begin{array}{l}8.4 \pm 0.7 \\
\quad(p=0.9584)\end{array}$ & 2 & 21.48 & $\begin{array}{l}15.4 \pm 0.7 \\
\quad(p=0.2187)\end{array}$ & 2 & 3.150 & $1.7 \pm 0.1(p=0.3322)$ & & 8.457 & $2.7 \pm 0.1(p>0.9999)$ & 2 & 3.742 \\
\hline SKO + Syt (12) & $\begin{array}{l}2.8 \pm 0.7^{* * *} \\
\quad(p=0.000035)\end{array}$ & 2 & 21.48 & $\begin{array}{l}19.2 \pm 2.1 \\
\quad(p=0.5328)\end{array}$ & 2 & 3.150 & $1.6 \pm 0.1^{*}(p=0.0100)$ & & 8.457 & $2.5 \pm 0.2(p=0.1061)$ & 2 & 3.742 \\
\hline Genotype autaptic cells $(n)$ & EPSC size (pA) & & Kruskal-Wallis & EPSC async. charge (pC) & & Kruskal-Wallis & & & & & & \\
\hline SKO (control; 25) & $466.1 \pm 64.3$ & & & $30 \pm 4$ & & & & & & & & \\
\hline TKO (22) & $\begin{array}{r}1128 \pm 222.6^{*} \\
(p=0.0322)\end{array}$ & 2 & 18.22 & $\begin{array}{l}63 \pm 13 \\
\quad(p=0.0922)\end{array}$ & 2 & 4.053 & & & & & & \\
\hline SKO + Syt1 (10) & $\begin{array}{l}3376 \pm 887^{* * *} \\
\quad(p=0.000063)\end{array}$ & 2 & 18.22 & $\begin{array}{l}44 \pm 15 \\
\quad(p>0.9999)\end{array}$ & 2 & 4.053 & & & & & & \\
\hline Genotype autaptic cells $(n)$ & $\begin{array}{l}\text { Normalized mEPSC } \\
\text { frequency }\end{array}$ & & Kruskal-Wallis & $\begin{array}{c}\text { Normalized mEPSC } \\
\text { amplitude }\end{array}$ & & Kruskal-Wallis & Normalized mEPSC rise time & & Kruskal-Wallis & $\begin{array}{l}\text { Normalized mEPSC decay } \\
\text { time }\end{array}$ & & Kruskal-Wallis \\
\hline TKO (control) (63) & $1 \pm 0.1$ & & & $1 \pm 0.03$ & & & $1 \pm 0.03$ & & & $1 \pm 0.03$ & & \\
\hline TKO + Doc2b (40) & $\begin{array}{l}0.46 \pm 0.07 * * * \\
\quad(p=0.000006)\end{array}$ & 3 & 28.41 & $\begin{array}{l}0.8 \pm 0.03 \\
\quad(p=0.167)\end{array}$ & 3 & 8.527 & $1 \pm 0.05(p>0.9999)$ & 3 & 2.485 & $1 \pm 0.05(p>0.9999)$ & 3 & 1.875 \\
\hline TKO + Doc2b $\mathrm{b}^{\mathrm{MID}}(9)$ & $\begin{array}{l}0.9 \pm 0.1 \\
\quad(p>0.9999)\end{array}$ & 3 & 28.41 & $\begin{array}{l}0.9 \pm 0.1 \\
\quad(p=0.4114)\end{array}$ & 3 & 8.527 & $0.9 \pm 0.06(p>0.9999)$ & 3 & 2.485 & $0.9 \pm 0.1(p=0.7457)$ & 3 & 1.875 \\
\hline $\mathrm{TKO}+\mathrm{Doc}^{\mathrm{DN}}{ }^{(9)}$ & $\begin{array}{l}1.1 \pm 0.2 \\
\quad(p>0.9999)\end{array}$ & 3 & 28.41 & $\begin{array}{l}0.9 \pm 0.05 \\
\quad(p>0.9999)\end{array}$ & 3 & 8.527 & $1.2 \pm 0.2(p=0.5603)$ & 3 & 2.485 & $1.1 \pm 0.1(p>0.9999)$ & 3 & 1.875 \\
\hline Genotype continental cells $(n)$ & $\begin{array}{l}\text { Normalized mEPSC } \\
\text { frequency }\end{array}$ & & Kruskal-Wallis & & & & & & & & & \\
\hline TKO (control; 82) & $1 \pm 0.07$ & & & & & & & & & & & \\
\hline TKO + Doc2b (77) & $\begin{array}{l}0.5 \pm 0.06^{* * *} \\
\quad(p<0.000001)\end{array}$ & 4 & 44.96 & & & & & & & & & \\
\hline TKO + Doc2a (31) & $\begin{array}{l}1 \pm 0.3^{*} \\
\quad(p=0.0153)\end{array}$ & 4 & 44.96 & & & & & & & & & \\
\hline 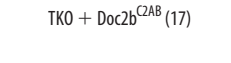 & $\begin{array}{l}1.8 \pm 0.4 \\
\quad(p=0.9818)\end{array}$ & 4 & 44.96 & & & & & & & & & \\
\hline TKO + Syt1 (27) & $\begin{array}{l}0.6 \pm 0.06 \\
\quad(p=0.1566)\end{array}$ & 4 & 44.96 & & & & & & & & & \\
\hline Genotype autaptic cells $(n)$ & $\begin{array}{l}\text { Normalized EPSC peak } \\
\text { amplitude }\end{array}$ & & Kruskal-Wallis & $\begin{array}{l}\text { Normalized EPSC } \\
\text { asynchronous charge }\end{array}$ & & Kruskal-Wallis & & & & & & \\
\hline TKO (control; 58) & $1 \pm 0.1$ & & & $1 \pm 0.16$ & & & & & & & & \\
\hline TKO + Doc2b (27) & $\begin{array}{l}0.6 \pm 0.1 \\
\quad(p=0.1462)\end{array}$ & 2 & 3.3323 & $\begin{array}{l}0.65 \pm 0.13 \\
\quad(p=0.0684)\end{array}$ & 2 & 4.487 & & & & & & \\
\hline $\mathrm{TK} 0+\mathrm{Doc}^{2 b^{\mathrm{DN}}}(12)$ & $0.8 \pm 0.1(p>0.9999)$ & 2 & 3.3323 & $0.7 \pm 0.15(p>0.9999)$ & 2 & 4.487 & & & & & & \\
\hline \multicolumn{13}{|l|}{ Figure 5} \\
\hline Genotype autaptic cells $(n)$ & $\begin{array}{l}\text { Normalized mEPSC } \\
\text { frequency }\end{array}$ & & Kruskal-Wallis & $\begin{array}{c}\text { Normalized mEPSC } \\
\text { amplitude }\end{array}$ & & Kruskal-Wallis & Normalized mEPSC rise time & & Kruskal-Wallis & $\begin{array}{l}\text { Normalized mEPSC decay } \\
\text { time }\end{array}$ & & Kruskal-Wallis \\
\hline SKO (control; 58) & $1 \pm 0.1$ & & & $1 \pm 0.03$ & & & $1 \pm 0.03$ & & & $1 \pm 0.02$ & & \\
\hline$S K 0+D o c 2 b(26)$ & $0.9 \pm 0.2(p=0.7289)$ & 3 & 11.35 & $1 \pm 0.07(p>0.9999)$ & 3 & 3.788 & $0.9 \pm 0.05(p=0.2735)$ & 3 & 3.776 & $0.9 \pm 0.04(p>0.9999)$ & 3 & 4.020 \\
\hline SKO + Syt ${ }^{2 \mathrm{CAB}}(26)$ & $0.8 \pm 0.1(p>0.9999)$ & 3 & 11.35 & $0.9 \pm 0.05(p=0.1824)$ & 3 & 3.788 & $0.9 \pm 0.04(p>0,9999)$ & 3 & 3.776 & $0.9 \pm 0.14(p=0.1564)$ & 3 & 4.020 \\
\hline SKO + Syt1 (7) & $\begin{array}{l}0.22 \pm 0.07^{* *} \\
\quad(p=0,0027)\end{array}$ & 3 & 11.35 & $\begin{array}{l}0.9 \pm 0.12 \\
\quad(p>0.9999)\end{array}$ & 3 & 3.788 & $0.9 \pm 0.13(p=0.6479)$ & 3 & 3.776 & $0.9 \pm 0.05(p>0.9999)$ & 3 & 4.020 \\
\hline Genotype continental cells $(n)$ & $\begin{array}{l}\text { Normalized mEPSC } \\
\text { frequency }\end{array}$ & & Kruskal-Wallis & $\begin{array}{l}\text { Normalized mEPSC } \\
\text { amplitude }\end{array}$ & & Kruskal-Wallis & Normalized mEPSC rise time & & Kruskal-Wallis & $\begin{array}{l}\text { Normalized mEPSC decay } \\
\text { time }\end{array}$ & & Kruskal-Wallis \\
\hline SKO (control; 20) & $1 \pm 0.13$ & & & $1 \pm 0.04$ & & & $1 \pm 0.05$ & & & $1 \pm 0.06$ & & \\
\hline SKO + Doc2b (33) & $\begin{array}{l}0.65 \pm 0.1^{*} \\
\quad(p=0.0387)\end{array}$ & 3 & 15.21 & $\begin{array}{l}1.1 \pm 0.06 \\
\quad(p>0.9999)\end{array}$ & 3 & 8.058 & $1.13 \pm 0.05(p=0.4392)$ & 3 & 14.09 & $1.13 \pm 0.06(p=0.5737)$ & 3 & 4.866 \\
\hline SKO + Doc2a (6) & $0.1 \pm 0.2(p>0.9999)$ & 3 & 15.21 & $\begin{array}{l}1.3 \pm 0.08^{*} \\
\quad(p=0.0475)\end{array}$ & 3 & 8.058 & $0.8 \pm 0.06(p=0.5051)$ & 3 & 14.09 & $0.97 \pm 0.08(p>0.9999)$ & 3 & 4.866 \\
\hline SKO + Syt1 (12) & $\begin{array}{l}0.3 \pm 0.08^{* *} \\
(p=0.0016)\end{array}$ & 3 & 15.21 & $\begin{array}{l}1.3 \pm 0.13 \\
\quad(p=0.1388)\end{array}$ & 3 & 8.058 & $0.7 \pm 0.06(p=0.1324)$ & 3 & 14.09 & $0.9 \pm 0.14(>0.9999)$ & 3 & 4.866 \\
\hline Genotype autaptic cells ( $n$ ) & Normalized EPSC size & & Kruskal-Wallis & & & & & & & & & \\
\hline SKO (control; 53) & $1 \pm 0.11$ & & & & & & & & & & & \\
\hline$S K 0+D o c 2 b(21)$ & $\begin{array}{l}1.1 \pm 0.22 \\
\quad(p>0.9999)\end{array}$ & 3 & 15.57 & & & & & & & & & \\
\hline SKO + Syt $^{\text {C2AB }}(26)$ & $\begin{array}{l}1.74 \pm 0.35 \\
\quad(p=0.1640)\end{array}$ & 3 & 15.57 & & & & & & & & & \\
\hline SKO + Syt1 (10) & $\begin{array}{l}10.8 \pm 5.7^{* * *} \\
\quad(p=0.0008)\end{array}$ & 3 & 15.57 & & & & & & & & & \\
\hline Genotype autaptic cells $(n)$ & EPSC size first pulse (pA) & & Kruskal-Wallis & EPSC size 10th pulse (pA) & & Kruskal-Wallis & $\begin{array}{l}\text { EPSC size first versus 10th (paired } \\
\text { measurements) }\end{array}$ & & & & & \\
\hline SKO (control) (15) & $628.2 \pm 180.7$ & & & $909.3 \pm 183$ & & & $\operatorname{SK}^{*}(p=0.021545)$ & & ilcoxon matched-pa & ed rank test ${ }^{a}$ & & \\
\hline SKO + Syt $^{2 A B}(13)$ & $\begin{aligned} & 790.2 \pm 237.3 \\
&(p>0.9999)\end{aligned}$ & 2 & 11.79 & $\begin{aligned} 2490.4 & \pm 373.4^{* *} \\
(p & =0.0032)\end{aligned}$ & 2 & 16.69 & $\begin{array}{l}\text { SKO }+ \text { Syt }^{(2 A B * * *} \\
\quad(p=0.000244)\end{array}$ & & ilcoxon matched-pa & ed rank test ${ }^{a}$ & & \\
\hline
\end{tabular}


Table 1. Continued

\begin{tabular}{|c|c|c|c|c|c|c|c|c|c|c|c|c|}
\hline & Parameter & df & Test $/ H$ & & df & Test $/ H$ & & $\mathrm{df}$ & \multicolumn{2}{|l|}{ Test $/ H$} & df & Test $/ H$ \\
\hline SKO + Syt1 (7) & $\begin{aligned} & 2707 \pm 610^{* *} \\
&(p=0.0022)\end{aligned}$ & 2 & 11.79 & $\begin{array}{l}3098 \pm 449.4^{* * *} \\
\quad(\text { vs control) } \\
(p=0.0006) ; \\
\text { n.s. (vs SKO }+ \\
\text { Syt } 2 \text { (2AB) } \\
(p=0.9860)\end{array}$ & 2 & 16.69 & SKO + Syt $(p=0.2188)$ & \multicolumn{5}{|c|}{ Wilcoxon matched-pairs signed rank test ${ }^{\mathrm{a}}$} \\
\hline Genotype autaptic cells $(n)$ & $\begin{array}{l}\text { EPSC first pulse } 10-90 \% \\
\quad \text { rise time (ms) }\end{array}$ & & Kruskal-Wallis & $\begin{array}{l}\text { EPSC 10th pulse 10-90\% } \\
\quad \text { rise time (ms) }\end{array}$ & & Kruskal-Wallis & $\begin{array}{l}\text { Rise time first vs 10th pulse } \\
\text { (paired measurements) }\end{array}$ & & & & & \\
\hline SKO (control) (15) & $21.2 \pm 2.2$ & & & $23 \pm 3.8$ & & & $\operatorname{SKO}(p=0.9999)$ & \multicolumn{5}{|c|}{ Wilcoxon matched-pairs signed rank test ${ }^{\mathrm{a}}$} \\
\hline SKO + Syt $^{(2 A B}(13)$ & $\begin{array}{l}9.1 \pm 3.1^{* *} \\
\quad(p=0.00483)\end{array}$ & 2 & 23.65 & $\begin{array}{l}2.4 \pm 0.2^{* * *} \\
\quad(p=0.000002)\end{array}$ & 2 & 31.17 & $\operatorname{SKO}+\operatorname{Syt}^{(2 A B}(p=0.108154)$ & \multicolumn{5}{|c|}{ Wilcoxon matched-pairs signed rank test ${ }^{\mathrm{a}}$} \\
\hline SKO + Syt1 (7) & $\begin{array}{l}2.1 \pm 0.2^{* * *} \text { vs control } \\
(p=0.000011) ; n \text {. S. } \\
\text { vs SKO + Syt } 2 \mathrm{CAB} \\
(p=0.390805)\end{array}$ & 2 & 23.65 & $\begin{array}{c}2.6 \pm 0.3^{* * *} \text { vs control } \\
(p=0.000026) ; \text { n.S. } \\
\text { vs SKO + Syt }{ }^{2 A B} \\
(p>0.999999)\end{array}$ & 2 & 31.17 & $\operatorname{SKO}+\operatorname{Syt}^{*}(p=0.0420)$ & \multicolumn{5}{|c|}{ Wilcoxon matched-pairs signed rank test ${ }^{\mathrm{a}}$} \\
\hline \multicolumn{13}{|l|}{ Figure 6} \\
\hline Genotype autaptic cells $(n)$ & $\begin{array}{l}\text { Normalized mEPSC } \\
\text { frequency }\end{array}$ & & Kruskal-Wallis & $\begin{array}{c}\text { Normalized mEPSC } \\
\text { amplitude }\end{array}$ & & Kruskal-Wallis & Normalized mEPSC rise time & & Kruskal-Wallis & $\begin{array}{l}\text { Normalized mEPSC decay } \\
\text { time }\end{array}$ & & Kruskal-Wallis \\
\hline SKO (control; 27) & $1 \pm 0.16$ & & & $1 \pm 0.04$ & & & $1 \pm 0.03$ & & & $1 \pm 0.04$ & & \\
\hline SKO + Syt1-Doc2b ${ }^{W T}(24)$ & $\begin{array}{l}1.2 \pm 0.17 \\
\quad(p=0.5254)\end{array}$ & 2 & 7.790 & $\begin{array}{l}1.1 \pm 0.05 \\
(p=0.4791)\end{array}$ & 2 & 9.855 & $0.8 \pm 0.04^{* *}(p=0.01)$ & 2 & 12.99 & $0.8 \pm 0.04(p=0.1115)$ & 2 & 10.86 \\
\hline SKO + Syt1-Doc2b ${ }^{\mathrm{DN}}(17)$ & $\begin{array}{l}1.7 \pm 0.2^{*} \\
(p=0.01054)\end{array}$ & 2 & 7.790 & $\begin{array}{l}1.2 \pm 0.06^{* *} \\
(p=0.0035)\end{array}$ & 2 & 9.855 & $1.1 \pm 0.05(p=0.7952)$ & 2 & 12.99 & $1.1 \pm 0.05(p=0.2139)$ & 2 & 10.86 \\
\hline Genotype continental cells $(n)$ & $\begin{array}{l}\text { Normalized mEPSC } \\
\text { frequency }\end{array}$ & & Kruskal-Wallis & $\begin{array}{l}\text { Normalized mEPSC } \\
\text { amplitude }\end{array}$ & & Kruskal-Wallis & Normalized mEPSC rise time & & Kruskal-Wallis & $\begin{array}{l}\text { Normalized mEPSC decay } \\
\text { time }\end{array}$ & & Kruskal-Wallis \\
\hline SKO (control; 20) & $1 \pm 0.17$ & & & $1 \pm 0.08$ & & & $1 \pm 0.08$ & & & $1 \pm 0.07$ & & \\
\hline SKO + Syt1-Doc2b ${ }^{\text {WT }}(30)$ & $1.4 \pm 0.2(p=0.4809)$ & 2 & 2.415 & $1 \pm 0.1(p>0.9999)$ & 2 & 0.7947 & $1.18 \pm 0.07(p=0.2751)$ & & 5.509 & $1.2 \pm 0.1(p=0.1080)$ & & 3.782 \\
\hline SKO + Syt1-Doc2b ${ }^{\mathrm{DN}}(26)$ & $1.5 \pm 0.2(p=0.2614)$ & 2 & 2.415 & $0.9 \pm 0.1(p=0.7487)$ & 2 & 0.7947 & $1.24 \pm 0.07(p=0.0383)$ & & 5.509 & $1.1 \pm 0.05(p=0.3633)$ & & 3.782 \\
\hline Genotype autaptic cells $(n)$ & Normalized EPSC size & & Kruskal-Wallis & & & & & & & & & \\
\hline SKO (control) (19) & $1 \pm 0.25$ & & & & & & & & & & & \\
\hline SKO + Syt1-Doc2b ${ }^{W T}(16)$ & $\begin{array}{l}0.5 \pm 0.07 \\
(p=0.3221)\end{array}$ & 2 & 9.055 & & & & & & & & & \\
\hline SKO + Syt1-Doc2b ${ }^{\mathrm{DN}}(15)$ & $\begin{array}{l}1.5 \pm 0.34 \\
\quad(p=0.1758)\end{array}$ & 2 & 9.055 & & & & & & & & & \\
\hline
\end{tabular}

Values of $p$ correspond to Dunn's adjusted $p$ values, except for paired tests where the Wilcoxon matched-pairs signed rank test was applied. ${ }^{*} p<0.05,{ }^{* *} p<0.01$, ${ }^{* * *} p<0.001$, n.s., not significant.

${ }^{a}$ Wilcoxon matched-pairs signed rank test was applied.

In most cases, the overexpressed constructs did not alter the mEPSC amplitude, which is primarily determined by postsynaptic processes. However, in SKO neurons expressing Doc2a, Syt1, or Syt1-Doc2 ${ }^{\text {DN }}$, a small but significant increase of the mEPSC amplitude was observed. In another study, Doc2a expressed in wild-type neurons did not affect the mEPSC amplitude (Yao et al., 2011a). Sytl expressed in SKO neurons also did not affect it (Tagliatti et al., 2020). Consistent with our data, mEPSC amplitude was unchanged by Syt1-Doc2 ${ }^{\mathrm{WT}}$ expressed in SKO neurons (Xue et al., 2015). Overall, we are reluctant to draw strong conclusions from the small effects on mEPSC amplitude.

Previous work also indicated that the $\mathrm{C} 2 \mathrm{AB}$ domain of Syt 1 is sufficient for eliciting synchronous release when targeted to the plasma membrane using GAP-43 (Yao et al., 2011b). In this work, we show that the soluble C2AB fragment of Syt1 is capable of driving synchronous release in a subset of Syt1-null neurons, and that this action appears to depend on synaptic activity and concurrent $\mathrm{Ca}^{2+}$ accumulation at the synaptic terminal. Recent work has characterized a role for Syt1 in tethering synaptic vesicles close to the active zone at rest (Chang et al., 2018). This action does not involve its $\mathrm{Ca}^{2+}$-binding regions but requires the polybasic side (K324-K327) and bottom residues (R398, R399) of the C2B domain, as well as an (at least partially) assembled SNARE complex. Upon AP induction and $\mathrm{Ca}^{2+}$ entry, the authors observed an increase in synaptic vesicle density at the active zone, an effect that depended on $\mathrm{Ca}^{2+}$ sensing by Syt1. We hypothesize that local accumulation of the soluble C2AB fragment of Syt1 at the active zone by a classical C2 activation mechanism could explain the partial rescue of synchronous release. The levels of soluble $\mathrm{C} 2 \mathrm{AB}$ fragments present at the active zone are likely to vary among synapses, giving rise to differences in the extent to which synchronous release is restored. In line with the aforementioned study, we observed a progressive increase in EPSC size as well as resynchronization of release upon synaptic activity, consistent with a $\mathrm{Ca}^{2+}$-dependent action of the $\mathrm{C} 2 \mathrm{AB}$ fragment in rapidly recruiting synaptic vesicles to the active zone and catalyzing fast release by bringing the synaptic vesicle membrane and plasma membrane closer together. Thus, we conclude that the transmembrane domain is crucial for reliable triggering of synchronous release, whereas the $\mathrm{C} 2 \mathrm{AB}$ fragment of Syt 1 alone requires membrane enrichment to carry out its $\mathrm{Ca}^{2+}$-dependent docking and bridging actions that trigger synchronous release.

In summary, we conclude that, despite their similarity, the $\mathrm{C} 2 \mathrm{AB}$ fragments of Doc $2 \mathrm{~b}$ and Syt 1 have divergent functions in driving spontaneous and synchronous neurotransmitter release, and that the high quantal release frequency in Syt1-null neurons relies on mechanisms independent of Doc2a/Doc2b.

\section{References}

Bacaj T, Wu D, Yang X, Morishita W, Zhou P, Xu W, Malenka RC, Südhof TC (2013) Synaptotagmin-1 and synaptotagmin-7 trigger synchronous and asynchronous phases of neurotransmitter release. Neuron 80:947-959.

Bourgeois-Jaarsma Q, Verhage M, Groffen AJ (2019) Doc2b Ca2 + binding site mutants enhance synaptic release at rest at the expense of sustained synaptic strength. Sci Rep 9:14408.

Broadie K, Bellen HJ, DiAntonio A, Littleton JT, Schwarz TL (1994) Absence of synaptotagmin disrupts excitation-secretion coupling during synaptic transmission. Proc Natl Acad Sci U S A 91:10727-10731.

Brose N, Petrenko AG, Südhof TC, Jahn R (1992) Synaptotagmin: a calcium sensor on the synaptic vesicle surface. Science 256:1021-1025.

Brouwer I, Giniatullina A, Laurens N, van Weering JRT, Bald D, Wuite GJL, Groffen AJ (2015) Direct quantitative detection of Doc2b-induced hemifusion in optically trapped membranes. Nat Commun 6:8387. 
Cao P, Maximov A, Südhof TC (2011) Activity-dependent IGF-1 exocytosis is controlled by the $\mathrm{Ca}(2+)$-sensor synaptotagmin-10. Cell 145:300-311.

Chang S, Trimbuch T, Rosenmund C (2018) Synaptotagmin-1 drives synchronous $\mathrm{Ca} 2+$-triggered fusion by C2B-domain-mediated synapticvesicle-membrane attachment. Nat Neurosci 21:33-40.

Courtney NA, Briguglio JS, Bradberry MM, Greer C, Chapman ER (2018) Excitatory and inhibitory neurons utilize different $\mathrm{Ca} 2+$ sensors and sources to regulate spontaneous release. Neuron 98:977-991.e5.

de Wit H, Walter AM, Milosevic I, Gulyás-Kovács A, Riedel D, Sørensen JB, Verhage M (2009) Synaptotagmin-1 docks secretory vesicles to syntaxin-1/ SNAP-25 acceptor complexes. Cell 138:935-946.

Duncan RR, Betz A, Shipston MJ, Brose N, Chow RH (1999) Transient, phorbol ester-induced DOC2-Munc13 interactions in vivo. J Biol Chem 274:27347-27350.

Emptage NJ, Reid CA, Fine A (2001) Calcium stores in hippocampal synaptic boutons mediate short-term plasticity, store-operated Ca2+ entry, and spontaneous transmitter release. Neuron 29:197-208.

Ermolyuk YS, Alder FG, Surges R, Pavlov IY, Timofeeva Y, Kullmann DM, Volynski KE (2013) Differential triggering of spontaneous glutamate release by P/Q-, N- and R-type $\mathrm{Ca}(2+)$ channels. Nat Neurosci 16:17541763.

Friedrich R, Groffen AJ, Connell E, van Weering JR, Gutman O, Henis YI, Davletov B, Ashery U, Weering JRT Van (2008) DOC2B acts as a calcium switch and enhances vesicle fusion. J Neurosci 28:6794-6806.

Friedrich R, Gottfried I, Ashery U (2013) Munc13-1 translocates to the plasma membrane in a Doc2B- and calcium-dependent manner. Front Endocrinol (Lausanne) 4:119.

Fukuda N, Emoto M, Nakamori Y, Taguchi A, Miyamoto S, Uraki S, Oka Y, Tanizawa Y (2009) DOC2B: A novel syntaxin-4 binding protein mediating insulin-regulated GLUT4 vesicle fusion in adipocytes. Diabetes 58: 377-384.

Geppert M, Goda Y, Hammer RE, Li C, Rosahl TW, Stevens CF, Südhof TC (1994) Synaptotagmin I: a major Ca2 + sensor for transmitter release at a central synapse. Cell 79:717-727.

Goda Y, Stevens CF (1994) Two components of transmitter release at a central synapse. Proc Natl Acad Sci U S A 91:12942-12946.

Groffen AJ, Brian EC, Dudok JJ, Kampmeijer J, Toonen RF, Verhage M (2004) $\mathrm{Ca}(2+)$-induced recruitment of the secretory vesicle protein DOC2B to the target membrane. J Biol Chem 279:23740-23747.

Groffen AJ, Friedrich R, Brian EC, Ashery U, Verhage M (2006) DOC2A and $\mathrm{DOC} 2 \mathrm{~B}$ are sensors for neuronal activity with unique calciumdependent and kinetic properties. J Neurochem 97:818-833.

Groffen AJ, Martens S, Díez Arazola R, Cornelisse LN, Lozovaya N, de Jong AP, Goriounova NA, Habets RL, Takai Y, Borst JG, Brose N, McMahon HT, Verhage M (2010) Doc2b is a high-affinity Ca2+ sensor for spontaneous neurotransmitter release. Science 327:1614-1618.

Gustavsson N, Lao Y, Maximov A, Chuang JC, Kostromina E, Repa JJ, Li C, Radda GK, Südhof TC, Han W (2008) Impaired insulin secretion and glucose intolerance in synaptotagmin-7 null mutant mice. Proc Natl Acad Sci U S A 105:3992-3997.

Gustavsson N, Wei SH, Hoang DN, Lao Y, Zhang Q, Radda GK, Rorsman P, Südhof TC, Han W (2009) Synaptotagmin-7 is a principal Ca2+ sensor for Ca2+-induced glucagon exocytosis in pancreas. J Physiol 587:11691178.

Higashio H, Nishimura N, Ishizaki H, Miyoshi J, Orita S, Sakane A, Sasaki T (2008) Doc2 alpha and Munc13-4 regulate $\mathrm{Ca}(2+)$-dependent secretory lysosome exocytosis in mast cells. J Immunol 180:4774-4784.

Hosaka M, Südhof TC (1999) Homo- and heterodimerization of synapsins. J Biol Chem 274:16747-16753.

Houy S, Groffen AJ, Ziomkiewicz I, Verhage M, Pinheiro PS, Sørensen JB (2017) Doc2B acts as a calcium sensor for vesicle priming requiring synaptotagmin-1, Munc13-2 and SNAREs. Elife 6:e27000.

Hui E, Johnson CP, Yao J, Dunning FM, Chapman ER (2009) Synaptotagmin-mediated bending of the target membrane is a critical step in $\mathrm{Ca}(2+)$-regulated fusion. Cell 138:709-721.

Kang R, Swayze R, Lise MF, Gerrow K, Mullard A, Honer WG, El-Husseini A (2004) Presynaptic trafficking of synaptotagmin I is regulated by protein palmitoylation. J Biol Chem 279:50524-50536.

Kochubey O, Schneggenburger R (2011) Synaptotagmin increases the dynamic range of synapses by driving $\mathrm{Ca}^{2}+$-evoked release and by clamping a near-linear remaining $\mathrm{Ca}^{2}+$ sensor. Neuron 69:736-748.
Littleton JT, Stern M, Schulze K, Perin M, Bellen HJ (1993) Mutational analysis of drosophila synaptotagmin demonstrates its essential role in $\mathrm{Ca}(2+)$-activated neurotransmitter release. Cell 74:1125-1134.

Liu H, Dean C, Arthur CP, Dong M, Chapman ER (2009) Autapses and networks of hippocampal neurons exhibit distinct synaptic transmission phenotypes in the absence of synaptotagmin I. J Neurosci 29:7395-7403

Llano I, González J, Caputo C, Lai FA, Blayney LM, Tan YP, Marty A (2000) Presynaptic calcium stores underlie large-amplitude miniature IPSCs and spontaneous calcium transients. Nat Neurosci 3:1256-1265.

Luo F, Südhof TC (2017) Synaptotagmin-7-mediated asynchronous release boosts high-fidelity synchronous transmission at a central synapse. Neuron 94:826-839.e3.

Martens S, Kozlov MM, McMahon HT (2007) How synaptotagmin promotes membrane fusion. Science 316:1205-1208.

Miyazaki M, Emoto M, Fukuda N, Hatanaka M, Taguchi A, Miyamoto S, Tanizawa Y (2009) DOC2b is a SNARE regulator of glucosestimulated delayed insulin secretion. Biochem Biophys Res Commun 384:461-465.

Mochida S, Orita S, Sakaguchi G, Sasaki T, Takai Y (1998) Role of the Doc2 alpha-Munc13-1 interaction in the neurotransmitter release process. Proc Natl Acad Sci U S A 95:11418-11422.

Orita S, Sasaki T, Naito A, Komuro R, Ohtsuka T, Maeda M, Suzuki H, Igarashi H, Takai Y (1995) Doc2: a novel brain protein having two repeated C2-like domains. Biochem Biophys Res Commun 206:439448.

Orita S, Naito A, Sakaguchi G, Maeda M, Igarashi H, Sasaki T, Takai Y (1997) Physical and functional interactions of Doc2 and Munc13 in Ca2+dependent exocytotic machinery. J Biol Chem 272:16081-16084.

Pang ZP, Bacaj T, Yang X, Zhou P, Xu W, Südhof TC (2011) Doc2 supports spontaneous synaptic transmission by a $\mathrm{Ca}(2+)$-independent mechanism. Neuron 70:244-251.

Pinheiro PS, de Wit H, Walter AM, Groffen AJ, Verhage M, Sørensen JB (2013) Doc2b synchronizes secretion from chromaffin cells by stimulating fast and inhibiting sustained release. J Neurosci 33:16459-16470.

Ramalingam L, Oh E, Yoder SM, Brozinick JT, Kalwat MA, Groffen AJ, Verhage M, Thurmond DC (2012) Doc2b is a key effector of insulin secretion and skeletal muscle insulin sensitivity. Diabetes 61:2424-2432.

Rickman C, Archer DA, Meunier FA, Craxton M, Fukuda M, Burgoyne RD, Davletov B (2004) Synaptotagmin interaction with the syntaxin/SNAP-25 dimer is mediated by an evolutionarily conserved motif and is sensitive to inositol hexakisphosphate. J Biol Chem 279:12574-12579.

Sakaguchi G, Orita S, Maeda M, Igarashi H, Takai Y (1995) Molecular cloning of an isoform of Doc2 having two C2-like domains. Biochem Biophys Res Commun 217:1053-1061.

Sakaguchi G, Manabe T, Kobayashi K, Orita S, Sasaki T, Naito A, Maeda M, Igarashi $\mathrm{H}$, Katsuura G, Nishioka $\mathrm{H}$, Mizoguchi A, Itohara S, Takahashi T, Takai Y (1999) Doc2 $\alpha$ is an activity-dependent modulator of excitatory synaptic transmission. Eur J Neurosci 11:4262-4268.

Schonn JS, Maximov A, Lao Y, Südhof TC, Sørensen JB (2008) Synaptotagmin- 1 and -7 are functionally overlapping $\mathrm{Ca} 2+$ sensors for exocytosis in adrenal chromaffin cells. Proc Natl Acad Sci U S A 105: $3998-4003$

Smith SM, Chen W, Vyleta NP, Williams C, Lee CH, Phillips C, Andresen MC (2012) Calcium regulation of spontaneous and asynchronous neurotransmitter release. Cell Calcium 52:226-233.

Südhof TC (2013) Neurotransmitter release: the last millisecond in the life of a synaptic vesicle. Neuron 80:675-690.

Sun J, Pang ZP, Qin D, Fahim AT, Adachi R, Südhof TC (2007) A dual$\mathrm{Ca} 2+$-sensor model for neurotransmitter release in a central synapse. Nature 450:676-682.

Tagliatti E, Bello OD, Mendonça PRF, Kotzadimitriou D, Nicholson E, Coleman J, Timofeeva Y, Rothman JE, Krishnakumar SS, Volynski KE (2020) Synaptotagmin 1 oligomers clamp and regulate different modes of neurotransmitter release. Proc Natl Acad Sci U S A. 117: $3819-3827$

Turecek J, Jackman SL, Regehr WG (2017) Synaptotagmin 7 confers frequency invariance onto specialized depressing synapses. Nature 551: 503-506.

Voets T, Moser T, Lund PE, Chow RH, Geppert M, Südhof TC, Neher E (2001) Intracellular calcium dependence of large dense-core vesicle exo- 
cytosis in the absence of synaptotagmin I. Proc Natl Acad Sci U S A 98:11680-11685.

Walter AM, Groffen AJ, Sørensen JB, Verhage M (2011) Multiple Ca2+ sensors in secretion: teammates, competitors or autocrats? Trends Neurosci 34:487-497.

Wang Z, Liu H, Gu Y, Chapman ER (2011) Reconstituted synaptotagmin I mediates vesicle docking, priming, and fusion. J Cell Biol 195:1159-1170.

Wierda KD, Sørensen JB (2014) Innervation by a GABAergic neuron depresses spontaneous release in glutamatergic neurons and unveils the clamping phenotype of synaptotagmin-1. J Neurosci 34:2100-2110.

Xu J, Mashimo T, Südhof TC (2007) Synaptotagmin-1, -2, and -9: Ca(2+) sensors for fast release that specify distinct presynaptic properties in subsets of neurons. Neuron 54:567-581.
Xu J, Pang ZP, Shin OH, Südhof TC (2009) Synaptotagmin-1 functions as a $\mathrm{Ca} 2+$ sensor for spontaneous release. Nat Neurosci 12:759-766.

Xue R, Gaffaney JD, Chapman ER (2015) Structural elements that underlie Doc $2 \beta$ function during asynchronous synaptic transmission. Proc Natl Acad Sci U S A 112:E4316-E4325.

Xue R, Ruhl DA, Briguglio JS, Figueroa AG, Pearce RA, Chapman ER (2018) Doc2-mediated superpriming supports synaptic augmentation. Proc Natl Acad Sci U S A 115:E5605-E5613.

Yao J, Gaffaney JD, Kwon SE, Chapman ER (2011a) Doc2 is a Ca2+ sensor required for asynchronous neurotransmitter release. Cell 147:666-677.

Yao J, Kwon SE, Gaffaney JD, Dunning FM, Chapman ER (2011b) Uncoupling the roles of synaptotagmin I during endo- and exocytosis of synaptic vesicles. Nat Neurosci 15:243-249. 